\title{
Longitudinal study reveals persistent environmental Salmonella Heidelberg in Brazilian broiler farms
}

\author{
Daiane Voss-Rech*, Beatris Kramer, Virgínia Santiago Silva, Raquel Rebelatto, \\ Paulo Giovani Abreu, Arlei Coldebella, Clarissa Silveira Luiz Vaz \\ Embrapa Suínos e Aves, BR 153, Km 110, Caixa Postal 321, 89715-899, Concordia, SC, Brazil
}

A R T I C L E IN F O

\section{Keywords:}

Salmonella Heidelberg

Broiler

Litter

Feed

Evaporative cooling system

\begin{abstract}
A B S T R A C T
The vast capacity for maintenance and dissemination in the environment are major challenges for the control of Salmonella spp. in poultry farms. The aim of this study was to assess environmental contamination by nontyphoidal Salmonella in successive broiler flocks in nine commercial broiler farms integrated with three companies in the south of Brazil, for a twelve-month production period. Recycled broiler litter, feed and swabs from the evaporative cooling system pads were analyzed, and the total enterobacteria count in the litter samples was ascertained. Positive broiler houses were identified in two of the three broiler companies studied, in which nontyphoidal Salmonella were detected for the first time in the first or second flock, and recurred in the recycled litter of subsequent flocks. Feed and evaporative cooling pad swab samples were also positive in at least one of the assessed flocks. The majority of the isolates (87.5\%) originating from different flocks, broiler houses and companies that were sampled were identified as $S$. Heidelberg, with the prevalence of one single genotype. The total enterobacteria levels in the litter diminished as the flocks progressed, but the presence of Salmonella spp. was constant over the course of time, indicating that the litter management procedures were not capable of interrupting the cycle of residual contamination. The predominance of $S$. Heidelberg highlights its emergence and dissemination in this region, as well as its resistance and maintenance in the environment, and reinforces the need to improve prevention and recycled litter management measures.
\end{abstract}

\section{Introduction}

Commercial broiler chicken production in Brazil has grown significantly in recent decades. Today, the country is the world's second biggest chicken producer and the leading chicken exporter (ABPA, 2018). However, this production boom has also brought constant sanitary challenges. Among relevant bacteria in poultry farming, Salmonella spp. remains the most significant, having poultry as its main reservoir. Systemic infection with non-typhoidal Salmonella serovars in chickens is transient and, with the exception of newly hatched chicks, causes little clinical disease (Barrow, 2000; Dar et al., 2017). However, human infection with non-typhoidal Salmonella remains a global public health concern despite efforts in biosecurity programs at broiler farms and food safety standards over recent decades (Dar et al., 2017).

The southern region of Brazil includes the most important broiler producing areas in the country, accounting for $64.4 \%$ of all slaughters in 2017 (ABPA, 2018). Studies have identified between a 5\% (Giombelli and Gloria, 2014; Voss-Rech et al., 2015) and 11\% (Pandini et al., 2015) positive result for non-typhoidal Salmonella in avian origin samples in this region, where $S$. Heidelberg, $S$. Hadar, $S$. Typhimurium, $S$. Mbandaka, $S$. Newport, $S$. Infantis and $S$. Senftenberg have been the most common in recent years (Pulido-Landínez et al., 2013; Pandini et al., 2015; Voss-Rech et al., 2015).

The introduction and dissemination of non-typhoidal Salmonella in broiler flocks include vertical transmission from the infected breeders, and horizontal transmission from preceding infected flocks or by other environmental sources, such as contaminated feed or drinking water (Dar et al., 2017). A contaminated broiler house can prove difficult to clean, which in turn may lead to contamination of the next flock of broilers (Rose et al., 2000). In this regard, the role of equipment that facilitates the build-up of dust in the broiler house has been overlooked in studies into the maintenance of pathogens between successive broiler flocks. This is the case for evaporative cooling systems which use pads, normally made of cellulose, to filter, humidify and cool large volumes of air that are moved through the shed in order to enhance the thermal comfort of the broilers. Furthermore, non-typhoidal Salmonella can persist for several months in the chicken's gastrointestinal tract (Beal et al., 2004) and survive for more than two years in litter and feed

\footnotetext{
* Corresponding author.

E-mail address: daiane.rech@embrapa.br (D. Voss-Rech).
} 
(Davies and Breslin, 2003). This makes the poultry litter an important reservoir for non-typhoidal Salmonella (Chinivasagam et al., 2009; Roll et al., 2011; Yamazaki et al., 2016; Voss-Rech et al., 2017; Buhr et al., 2017), especially when the litter is reused without any interventions that neutralize residual pathogens (Vaz et al., 2017).

The presence of non-typhoidal Salmonella in environmental samples from broiler farms is correlated to infection in the broilers and contamination of the carcasses at slaughter (Berghaus et al., 2013; Yamazaki et al., 2016). During pre-slaughter operations and transport, stress can lead to increased shedding and close proximity of other broilers in crates can result in extensive cross contamination (Marin and Lainez, 2009). On the other hand, monitoring is essential to determine Salmonella prevalence at pre-harvest stage, where analysis of environmental samples is considered a more efficient means of detecting nontyphoidal Salmonella than that of individual feces (Mueller-Doblies et al., 2009). Long-term studies are useful for determining the dynamics of contamination by non-typhoidal Salmonella in broiler houses and for identifying points at which additional control measures are required in the growing farms (Volkova et al., 2010; Berghaus et al., 2013). Hence, this study was aimed at investigating the occurrence of non-typhoidal Salmonella in commercial broiler houses in the south of Brazil for a oneyear production period. Serotyping and genotyping were conducted to characterize the diversity and clonal relationships of the isolates.

\section{Materials and methods}

\subsection{Experimental design and sampling}

Nine commercial broiler houses were assessed, through six consecutive flocks in each, 54 flocks in total. The broiler houses were located in different broiler farms in the south of Brazil, with an average placement capacity of approximately 20,000 broilers, operating an all in/all out management system and recycling litters between flocks. The farms were integrated into three companies: A (sheds 1, 5 and 6), B (sheds 2, 3 and 4) and C (sheds 7, 8 and 9). Broiler chicks were provided by three separate hatcheries, each from a different broiler company. The first flock of broilers was housed on a new pine shavings litter, which was recycled for subsequent flocks. The downtime between flocks varied from 3 to 26 days, during which period residual feathers were burned and the litter was stirred using a poultry litter scarifier equipment. Eight litter samples were taken from each broiler house and flock - four prior to placement and four at harvest of the broilers; and five feed samples were taken over the course of the rearing period. Five of the sampled houses were equipped with evaporative cooling systems, from which four swabs from the pads were collected, two on placement and two at harvest of the broilers, for each flock. Litter samples and swabs from the evaporative cooling pads were collected from broiler houses before ( $~ 4 \mathrm{~h}$ ) housing and removing the broilers. A total of 812 samples were analyzed, 442 from litter, 270 from feed, and 120 swabs from evaporative cooling pads.

For the litter sampling, the broiler houses were split into four equal quadrants, within which a pool composed of ten sub-samples weighing roughly $50 \mathrm{~g}$ was collected in equidistant manner and stored in new plastic bags, totaling four samples per broiler house for each flock. The feed samples were collected at the silo conveyor outlet. Each sample weighed roughly $500 \mathrm{~g}$ and were stored in plastic bags. The swabs from evaporative cooling pads were collected by wiping a sterile swab along the surface and then stored in sterile tubes. All the samples were transported to the laboratory in insulated boxes with ice packs and processed within $48 \mathrm{~h}$.

\subsection{Salmonella isolation and serotyping}

For isolation of Salmonella spp., $25 \mathrm{~g}$ of the broiler litter and/or feed were pre-enriched in $225 \mathrm{ml}$ of buffered peptone water (BPW). The evaporative cooling pad swabs were pre-enriched in $5 \mathrm{ml}$ of BPW and incubated at $37^{\circ} \mathrm{C} / 24 \mathrm{~h}$. Of the pre-enriched cultures $0.1 \mathrm{ml}$ was transferred to Rappaport-Vassiliadis broth (Merck, Germany) and $1 \mathrm{ml}$ to Muller-Kauffmann tetrathionate broth (Oxoid, UK) and incubated at $42^{\circ} \mathrm{C} / 24 \mathrm{~h}$. One loopful of each broth was streaked onto plates of brilliant green agar (Oxoid, UK) containing novobiocin $(40 \mathrm{mg} / \mathrm{L}$ ) (Merck, Germany), and in xylose lysine tergitol-4 agar (XLT4) (Difco, UK) and incubated at $37^{\circ} \mathrm{C} / 48 \mathrm{~h}$. Suggestive colonies of Salmonella spp. were subcultured onto nutrient agar (Himedia, India) and subjected to biochemical identification and serological confirmation.

From each sampling phase, one Salmonella isolate from each broiler house, flock and matrix was selected for serotyping, totaling 40 strains. Antigenic characterization was conducted at the National Reference Laboratory for Cholera and Enteric Diseases of the Instituto Oswaldo Cruz (FIOCRUZ, Rio de Janeiro, Brazil) by means of rapid slide agglutination tests, using somatic and flagellar antisera produced by the laboratory.

\subsection{Pulsed-field gel electrophoresis analysis}

The serotyped Salmonella isolates were genotyped by DNA macrorestriction analysis, as previously described (Ribot et al., 2006). Salmonella Braenderup H9812 (ATCC BAA-664) was used as the molecular-weight size marker. The fragments of the restriction were separated by pulsed-field gel electrophoresis analysis (PFGE) on TBE $0.5 \mathrm{X}$ at $14^{\circ} \mathrm{C}$, using the CHEF Mapper XA system (BioRad, USA). Pulses were alternated between 2.2 and $63.8 \mathrm{~s}$ at $6 \mathrm{~V} / \mathrm{s}$ for $22 \mathrm{~h}$. The gel was stained with ethidium bromide $(1 \mu \mathrm{g} / \mathrm{mL})$ and viewed under ultraviolet light. The images were recorded digitally and the DNA macrorestriction patterns were compared by the software Bionumerics 6.1 (Applied Maths, Belgium). Similarity was calculated by the Dice coefficient with a $1.7 \%$ band position tolerance (Carriço et al., 2005) and the dendrogram generated by cluster analysis using the unweighted pair group method with arithmetic averages (UPGMA).

\subsection{Viable counts of Enterobacteria}

The litter samples were subjected to enterobacteria counts, for which $10 \mathrm{~g}$ of broiler litter were diluted in $90 \mathrm{ml}$ of phosphate-buffered saline (PBS), $\mathrm{pH} 7.4$, homogenized in an orbital shaker at $140 \mathrm{rpm}$ for $10 \mathrm{~min}$ and then submitted to serial decimal dilutions. From each dilution $0.1 \mathrm{ml}$ was distributed onto MacConkey agar plates (Prodimol, Brazil) and incubated at $37^{\circ} \mathrm{C} / 48 \mathrm{~h}$. Colonies were counted in the plates that presented between 30 and 300 colonies and corrected by the corresponding dilution factor. The detection limit of the method was 100 $\mathrm{CFU} / \mathrm{g}$.

\subsection{Statistical analysis}

The mean enterobacteria counts of each broiler house and flock were converted into a logarithmic scale and subjected to repeated measures analysis for each evaluation phase (placement and harvest), considering the flock effect and 16 types of variance and covariance matrix structures, using PROC MIXED of the Statistical Analysis System (C) (SAS Institute Inc., 2012, North Carolina, USA), as in Xavier (2000). The structure used in the analysis was chosen based on the lowest value of the Akaike Information Criterion (AIC). The maximum likelihood estimation method was used. Analytical breakdown for the flock effect was achieved through polynomial regression analysis. Effects of flock, broiler company and downtime period on the prevalence of Salmonella in the placement and harvest were evaluated by logistic regression analysis using the SAS LOGISTIC procedure. 
Table 1

Distribution of Salmonella spp. in broiler flocks per shed and company.

\begin{tabular}{|c|c|c|c|c|c|}
\hline Shed $^{\mathrm{a}}$ & Company & Sample & Flock & Serovar & Genotype \\
\hline 1 & A & litter & $\begin{array}{l}2^{\text {nd }}, 3^{\text {rd }}, 4^{\text {th }}, 5^{\text {th }}, \\
6^{\text {th }}\end{array}$ & $S$. Heidelberg & D \\
\hline 6 & A & litter & $\begin{array}{l}2^{\text {nd }}, 3^{\text {rd }}, 4^{\text {th }}, 5^{\text {th }} \\
6^{\text {th }}\end{array}$ & S. Heidelberg & $\mathrm{D}$ \\
\hline \multirow[t]{3}{*}{7} & $\mathrm{C}$ & litter & $1^{\text {st }}, 2^{\text {nd }}, 4^{\text {th }}, 6^{\text {th }}$ & S. Heidelberg & $\mathrm{D}$ \\
\hline & & feed & $6^{\text {th }}$ & S. Mbandaka & $\mathrm{F}$ \\
\hline & & $\mathrm{ECP}^{\mathrm{b}}$ & $4^{\text {th }}$ & S. enterica $0: 4,5$ & $\mathrm{D}$ \\
\hline \multirow[t]{2}{*}{8} & $\mathrm{C}$ & litter & $1^{\text {st }}, 2^{\text {nd }}, 3^{\text {rd }}, 4^{\text {th }}$ & $S$. Heidelberg & A, C \\
\hline & & & $6^{\text {th }}$ & S. Mbandaka & B \\
\hline \multirow[t]{3}{*}{9} & $\mathrm{C}$ & litter & $1^{\text {st }}$ & S. enterica $\mathrm{O}: 4,5$ & $\mathrm{D}$ \\
\hline & & & $\begin{array}{l}2^{\text {nd }}, 3^{\text {rd }}, 4^{\text {th }}, 5^{\text {th }}, \\
6^{\text {th }}\end{array}$ & $S$. Heidelberg & $\mathrm{D}, \mathrm{E}$ \\
\hline & & feed & $1^{\text {st }}$ & $\begin{array}{l}\text { S. enterica } \\
\text { O: } 4,5:-: 1,2\end{array}$ & $\mathrm{D}$ \\
\hline
\end{tabular}

${ }^{\text {a }}$ Samples from sheds 2, 3, 4 (company B) and 5 (company A) tested negative throughout the evaluated period.

b ECP: Evaporative cooling pad.

\section{Results}

\subsection{Non-typhoidal Salmonella were detected in broiler litter through successive flocks}

In total, $120(28.4 \%)$ litter samples, $2(0.74 \%)$ feed samples and 1 (0.83\%) evaporative cooling pad swab were positive for Salmonella spp. All the positive samples originated from five of the nine analyzed sheds, belonging to two companies (A and $\mathrm{C}$ ). The three sheds belonging to company B remained negative throughout the study period. All the samples from fresh litter, assessed upon placement of the first flock, were negative for Salmonella spp. In the positive sheds, litter contamination was detected in the first or second flocks and remained through, at least, four subsequent flocks (Table 1). There were no significant differences $(\mathrm{p}>0.05)$ in the prevalence of Salmonella in the litters over the progression of the flocks, neither for the evaluations on placement, nor for those at harvest of the broilers. Likewise, no correlation was found between downtime period and the prevalence of Salmonella in the successive flocks housed in each broiler house. Considering the 54 flocks analyzed in the different sheds, the litters of 13 flocks were positive for Salmonella in the placement phase, which number increased to 24 at harvest (Table 2). In two sheds (7 and 9, company $\mathrm{C}$ ) the bacteria were detected in the feed, and also isolated from the evaporative cooling pads of shed 7 (Table 1).

\subsection{Clonal strains of S. Heidelberg were prevalent in different broiler houses}

$S$. Heidelberg was the most frequent serovar $(87.5 \%, 35 / 40)$. All the isolates from company A were identified as $S$. Heidelberg and in company C, in addition to $S$. Heidelberg, two isolates (obtained from feed and litter) were identified as $S$. Mbandaka, and three isolates (obtained from litter, feed and evaporative cooling pads) presented incomplete antigenic characterization.

Six DNA macrorestriction profiles were identified (A to F), of which one genotype of $S$. Heidelberg was predominant, occurring in the litter throughout the flocks in four sheds (1, 6, 7 and 9) of two distinct companies (Fig. 1). In company C, Salmonella strains with incomplete antigenic characterization isolated from feed samples from shed 9 and from the evaporative cooling pads of shed 7 shared an indistinguishable pattern among the predominant $S$. Heidelberg genotype (Fig. 1), whereas the $S$. Mbandaka genotype identified in the feed of shed 7 was not observed in any other sample. The $S$. Heidelberg isolates from shed 8 displayed genetic similarity ( $>92 \%$ ) with $S$. Heidelberg isolated from the other sheds.

\subsection{The level of Enterobacteria in the litter diminished over the progression of the flocks}

The mean enterobacteria count in the litter of each broiler house at the placement and harvest phases is presented in Fig. 2. There was a significant flock effect ( $\mathrm{p} \leq 0.05)$ for the evaluations conducted, both at the placement and harvest of the broilers. The average enterobacteria count in the litter showed linear reduction as the successive flocks of broilers were placed in the broiler house, as presented in Fig. 2.

\section{Discussion}

In this temporal population fluctuation analysis of non-typhoidal Salmonella in commercial broiler houses all the fresh litter samples collected at placement of the first flock were negative for Salmonella. However, in the positive broiler houses, the first detection of Salmonella in litter occurred at the harvest of the first flock or in the recycled litter collected from the second flock (Table 2). After that first detection, Salmonella was isolated from the litters of subsequent flocks in the same broiler house. This finding is interesting because the frequency of Salmonella spp. in the litter at harvest of the broilers increases the probability of contamination of carcasses during processing (Volkova et al., 2010). Moreover, contaminated litter facilitates the reintroduction of Salmonella spp. after the downtime between flocks in the broiler house when other biosecurity measures are also inefficient (Mueller-Doblies et al., 2014). Indeed, the broiler farms monitored in this study practiced litter recycling, yet without applying a specific in-house treatment to inactivate residual microorganisms, such as windrowing, shallow fermentation, or addition of chemical additives (Vaz et al., 2017), which would seem to favor the maintenance of non-typhoidal Salmonella in the litter, and constituting a source of contamination for subsequent flocks. However, the same recycled litter management between flocks was practiced at the farms where the broiler houses were negative,

Table 2

Presence of Salmonella spp. in litter at placement and harvest of each broiler flock (number of positives/total samples).

\begin{tabular}{|c|c|c|c|c|c|c|c|c|c|c|c|c|c|c|c|c|c|}
\hline \multirow[t]{2}{*}{ Shed $^{\mathrm{a}}$} & \multicolumn{2}{|c|}{ Flock 1} & \multirow{2}{*}{$\begin{array}{l}\text { Downtime } \\
\text { (days) }\end{array}$} & \multicolumn{2}{|l|}{ Flock 2} & \multirow{2}{*}{$\begin{array}{l}\text { Downtime } \\
\text { (days) }\end{array}$} & \multicolumn{2}{|c|}{ Flock 3} & \multirow{2}{*}{$\begin{array}{l}\text { Downtime } \\
\text { (days) }\end{array}$} & \multicolumn{2}{|c|}{ Flock 4} & \multirow{2}{*}{$\begin{array}{l}\text { Downtime } \\
\text { (days) }\end{array}$} & \multicolumn{2}{|c|}{ Flock 5} & \multirow{2}{*}{$\begin{array}{l}\text { Downtime } \\
\text { (days) }\end{array}$} & \multicolumn{2}{|c|}{ Flock 6} \\
\hline & $\mathrm{P}^{\mathrm{b}}$ & $\mathrm{H}^{\mathrm{c}}$ & & $\mathrm{P}$ & $\mathrm{H}$ & & $\mathrm{P}$ & $\mathrm{H}$ & & $\mathrm{P}$ & $\mathrm{H}$ & & $\mathrm{P}$ & $\mathrm{H}$ & & $\mathrm{P}$ & $\mathrm{H}$ \\
\hline 1 & $\mathrm{NA}^{\mathrm{d}}$ & $0 / 4$ & 13 & $2 / 4$ & $0 / 4$ & 20 & $0 / 4$ & $4 / 4$ & 8 & $3 / 4$ & $4 / 4$ & 14 & $2 / 4$ & $4 / 4$ & 9 & $4 / 4$ & $4 / 4$ \\
\hline 6 & $0 / 4$ & $0 / 4$ & 8 & $0 / 4$ & $4 / 4$ & 14 & $3 / 4$ & $4 / 4$ & 9 & $2 / 4$ & $4 / 4$ & 26 & $2 / 4$ & $4 / 4$ & 26 & $1 / 4$ & $4 / 4$ \\
\hline 7 & $0 / 1^{\mathrm{e}}$ & $4 / 4$ & 23 & $3 / 4$ & $4 / 4$ & 21 & $0 / 4$ & $0 / 4$ & 19 & $0 / 4$ & $2 / 4$ & 19 & $0 / 4$ & $0 / 4$ & 14 & $0 / 4$ & $1 / 4$ \\
\hline 8 & $0 / 1^{\mathrm{e}}$ & $4 / 4$ & 19 & $3 / 4$ & $4 / 4$ & 21 & $0 / 4$ & $4 / 4$ & 21 & $2 / 4$ & $4 / 4$ & 19 & $0 / 4$ & $0 / 4$ & 17 & $0 / 4$ & $3 / 4$ \\
\hline 9 & $0 / 4$ & $4 / 4$ & 11 & $4 / 4$ & $4 / 4$ & 18 & $0 / 4$ & $4 / 4$ & 22 & $2 / 4$ & $4 / 4$ & 21 & $0 / 4$ & $4 / 4$ & 16 & $0 / 4$ & $1 / 4$ \\
\hline Total & $0 / 10$ & $12 / 20$ & & $12 / 20$ & $16 / 20$ & & $3 / 20$ & $16 / 20$ & & $9 / 20$ & $18 / 20$ & & $4 / 20$ & $12 / 20$ & & $5 / 20$ & $13 / 20$ \\
\hline
\end{tabular}

a Sheds 2, 3, 4 (company B) and 5 (company A) remained negative throughout the evaluated period and downtime varied from 3 to 20 days.

b P: placement.

c $\mathrm{H}$ : harvest.

d NA: not analyzed.

e The four samples received at the laboratory were processed in pool. 


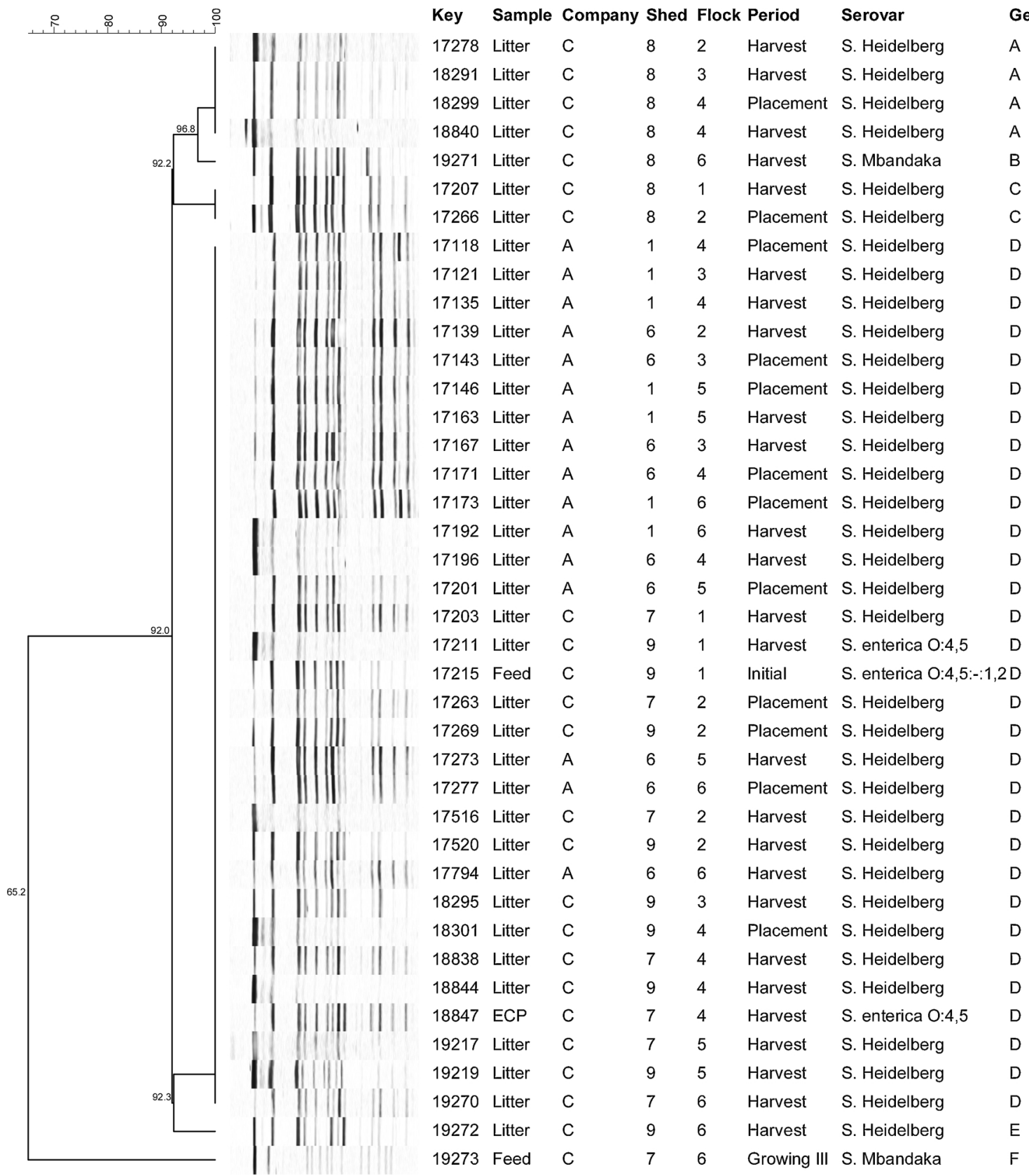

Fig. 1. Dendrogram of the PFGE profiles identified in the Salmonella spp. strains isolated from broiler litter, feed and evaporative cooling pads (ECP).

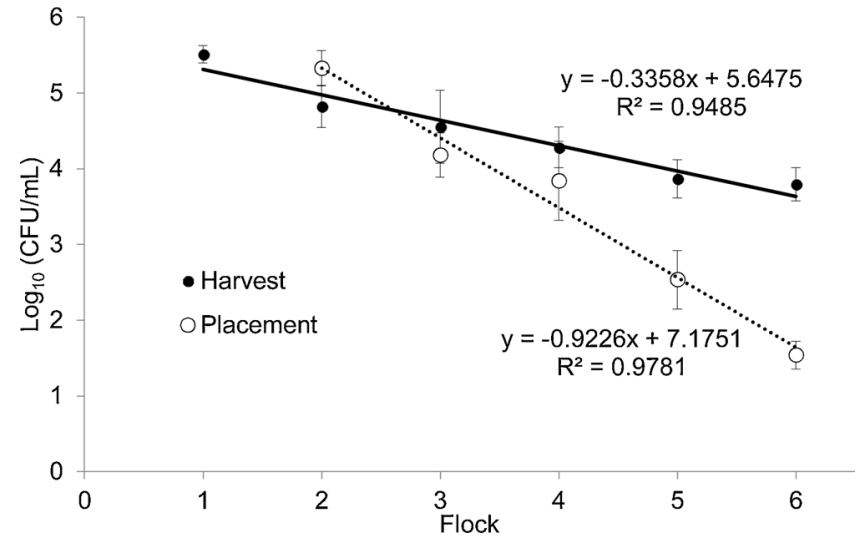

Fig. 2. Mean profiles of enterobacteria count in recycled broiler litter in function of successive flocks. suggesting that there were other effective biosecurity factors for avoiding contamination by non-typhoidal Salmonella in those broiler houses over the course of the production period monitored. Likewise, non-typhoidal Salmonella environmental contamination could have originated from infected day-old broiler chicks raised in the studied broiler houses, which, however, was not evaluated in this study.

In the broiler houses that were positive for non-typhoidal Salmonella, the bacteria were not detected in some flocks, especially in the placement phase. Intermittent detection of Salmonella in the environment has been previously reported (Gradel and Rattenborg, 2003; Pedersen et al., 2008). Placement of the chicks in the broiler house is preceded by a downtime period between flocks that would influences the level of residual contamination, below the Salmonella spp. detection limit, resulting in a low infection pressure for the subsequent flock. However, poultry might be colonized by low concentrations of Salmonella (Van Immerseel et al., 2004) and the bacteria can also persist in places where the broilers' exposure is low or indirect (Pedersen et al., 
2008). The introduction of a new flock of broilers favors proliferation of the bacteria in the intestinal tract and at the end of the production cycle there are increased contamination levels and chances of detection, as we can observe in Table 2. The broiler farms sampled in this study practiced different downtime periods between flocks, which, however, did not have an influence in the non-typhoidal Salmonella prevalence.

$S$. Heidelberg has previously been described in poultry in Brazil (Pulido-Landínez et al., 2013; Pandini et al., 2015; Voss-Rech et al., 2015). The prevalence of $S$. Heidelberg (87.5\%) in this study highlights its emergence in broiler farms in the south of Brazil in relation to other serovars. Some Salmonella serovars are more resistant than others in the environment (Chinivasagam et al., 2009; Andino et al., 2014), to the broiler house cleaning and disinfection procedures (Mueller-Doblies et al., 2014), with greater colonization ability (Buhr et al., 2017), and greater biofilm formation capacity, hindering their elimination from installations and equipment (Marin et al., 2009). Notably, S. Heidelberg persisted in the recycled broiler litter, treated by shallow fermentation and the addition of quicklime during the 14-day downtime between flocks, remaining capable of colonizing the subsequently housed broilers (Voss-Rech et al., 2017). Genomic analyses of $S$. Heidelberg strains isolated from the broiler litter, hatchery (Deblais et al., 2018) and human outbreaks (Hoffmann et al., 2014) demonstrate the presence of genetic elements, such as genes associated to cell signaling and regulation; phosphorus and nitrogen metabolism; motility and chemotaxis; and several virulence factors carried in bacteriophages or plasmids. The presence of genes associated to the type IV secretion system (T4SS) indicates that this system is functional in these $S$. Heidelberg strains and underlines a probable ability to acquire foreign DNA by horizontal transfer between bacteria (Deblais et al., 2018). In fact, the broiler litter acts like an extra-intestinal environment for the natural selection of $S$. Heidelberg strains, allowing for the adaptation and expression of newly acquired virulence factors that influence this resistance capacity in the environment and render usual preventive management practices at farms less effective (Oladeinde et al., 2018).

The identification of an indistinguishable $S$. Heidelberg genotype in litter samples and detected repeatedly throughout the flocks in the broiler houses of two companies (Fig. 1) reinforces the difficulty of eliminating this serovar from the environment in broiler farms and demonstrates the dispersion of this clone in the study region. PFGE is a DNA fingerprinting method based on the restriction of genomic DNA and is currently considered the gold-standard for the subtyping of Salmonella (Cosby et al., 2015), the strains of which with indistinguishable profiles can be classified as epidemiologically linked with a high degree of confidence (Cosby et al., 2015). More refined methods, such as whole genome sequencing (WGS) and single-nucleotide polymorphisms (SNPs) analysis, are capable of identifying subtle differences between highly clonal strains of $S$. Heidelberg, however they still have much higher costs in developing countries, and hence more suited to investigations into outbreaks in humans and studies on the short-term evolution of epidemic clones (Hoffmann et al., 2014).

$S$. Mbandaka and $S$. enterica $0: 4,5:-: 1,2$ were isolated from the feed supplied to the broilers in two of the sampled broiler houses (Table 1). Feed is considered a key source of Salmonella spp. for broiler flocks (Barrow, 2000; Andino et al., 2014), where the presence of bacteria would indicate that some stage of the manufacture process was inefficient or that cross contamination has occurred at a later stage (Barrow, 2000). The identification of one genetically distinct $S$. Mbandaka strain, isolated exclusively from the feed (Fig. 1), would suggest that contamination had occurred in the production or transport and not through cross contamination of the feed in the broiler house. In general, the frequency of Salmonella spp. in feed samples was low in this study. There are several factors that interfere in the detection of Salmonella in feed, including the non-uniform distribution of the bacteria; cellular injury and detection limits of the laboratorial methods used for dry matrices (Alali and Hofacre, 2016). However, the importance of this finding lies in the fact that, in the commercial broiler production system, manufacturers supply feed to several broiler farms, pointing to the high potential of spreading pathogens. In addition, one Salmonella strain with incomplete antigenic characterization $(0: 4,5)$ was detected in the evaporative cooling pads of shed 7 and presented the predominant genotype (D) found in the $S$. Heidelberg strains (Fig. 1), demonstrating a correlation with the contamination detected in the broiler litter. In fact, the evaporative cooling system promotes circulation of bacteria present in the broiler house dust, the origins of which include the broiler litter (Chinivasagam et al., 2009).

Notably, the mean variation of enterobacteria in the broiler litter from the first to sixth flock $\left(5.33 \pm 0.23\right.$ to $1.54 \pm 0.18 \log _{10} \mathrm{CFU} / \mathrm{g}$ at placement and $5.51 \pm 0.12$ to $3.79 \pm 0.22 \log _{10} \mathrm{CFU} / \mathrm{g}$ at harvest) shows reduction over the course of flocks (Fig. 2). Similar results have been reported in other studies (Thaxton et al., 2003; Vaz et al., 2017). The temporal effect on the reduction of enterobacterial load in recycled litter has been attributed to the reduced water activity (Chinivasagam et al., 2009), increased ammonia level (Roll et al., 2011; Voss-Rech et al., 2017) and microbiota stabilization (Thaxton et al., 2003). On the other hand, the frequency of Salmonella in those same samples did not change in the six evaluated flocks. By comparison, Roll et al. (2011) only observed significant reduction in the frequency of Salmonella spp. in recycled litters from the sixth flock onwards, in a longer period to that evaluated in this study. The linear reduction of residual enterobacteria, allied to the fact that the litter in four broiler houses monitored remained negative for non-typhoidal Salmonella throughout the study period, demonstrates that litter recycling results in better microbiological quality when compared to the fresh litter of the first flock. Nonetheless, the option to safely recycle litter depends on the absence of sanitary problems with the broilers and the use of a proven effective treatment method to deactivate residual microorganisms during the downtime between flocks (Vaz et al., 2017).

\section{Conclusion}

The persistence of non-typhoidal Salmonella in recycled litter over the course of the evaluated production period indicates that the residual feathers burning and the litter stirring procedure was not capable of interrupting the cycle of residual contamination. The decision to recycle broiler litter needs to be tied to the sanitary history of the previous flocks and the epidemiological situation of the broiler farm, especially upon the occurrence of non-typhoidal Salmonella serovars with the ability to resist in the environment. Furthermore, litter recycling should be conditioned to the use of proven effective treatment for deactivating residual bacteria. The presence of non-typhoidal Salmonella in a limited number of feed samples and evaporative cooling pad suggests a minor role in the Salmonella contamination detected within the studied broiler houses. Finally, the emergence of $S$. Heidelberg in broiler farms in the south of Brazil must be highlighted. Complementary studies, such as WGS analysis, should investigate the clonality of the PFGE patterns identified in the $S$. Heidelberg isolates, seeking to understand questions related to their predominance in the region.

\section{Acknowledgements}

This work was supported by the Brazilian Agricultural Research Corporation - Embrapa, grant number 0313100900. We gratefully thank the broiler companies for granting access to the farms.

\section{References}

ABPA, 2018. Brazilian Association of Animal Protein, 2018. Annual Report. São Paulo, Available at:. . http://abpa-br.com.br/storage/files/relatorio-anual-2018.pdf.

Alali, W., Hofacre, C.L., 2016. Preharvest food safety in broiler chicken production. Microbiol. Spectrum 4 (4), 0002-2014. https://doi.org/10.1128/microbiolspec.PFS0002-2014.

Andino, A., Pendleton, S., Zhang, N., Chen, W., Critzer, F., Hanning, I., 2014. Survival of Salmonella enterica in poultry feed is strain dependent. Poult. Sci. 93, 441-447. 
https://doi.org/10.3382/ps.2013-03401.

Barrow, P.A., 2000. The paratyphoid salmonellae. Rev. Sci. Tech. 9 (2), 351-375.

Beal, R.K., Wigley, P., Powers, C., Hulme, S.D., Barrow, P.A., Smith, A.L., 2004. Age at primary infection with Salmonella enterica serovar Typhimurium in the chicken influences persistence of infection and subsequent immunity to re-challenge. Vet. Immunol. Immunopathol. 100 (3-4), 151-164. https://doi.org/10.1016/j.vetimm. 2004.04.005.

Berghaus, R.D., Thayer, S.G., Law, B.F., Mild, R.M., Hofacre, C.L., Singerc, R.S., 2013. Enumeration of Salmonella and Campylobacter spp. in environmental farm samples and processing plant carcass rinses from commercial broiler chicken flocks. Appl. Environ. Microbiol. 79 (13), 4106-4114. https://doi.org/10.1128/AEM.00836-13.

Buhr, R.J., Bourassa, D.V., Hinton Jr., A., Fairchild, B.D., Ritz, C.W., 2017. Impact of litter Salmonella status during feed withdrawal on Salmonella recovery from the broiler crop and ceca1. Poult. Sci. 96 (12), 4361-4369. https://doi.org/10.3382/ps/pex231.

Carriço, J.A., Pinto, F.R., Simas, C., Nunes, S., Sousa, N.G., Franzão, N., de Lencastre, H., Almeida, J.S., 2005. Assessment of band-based similarity coefficients for automatic type and subtype classification of microbial isolates analyzed by pulsed-field gel electrophoresis. J. Clin. Microbiol. 43 (11), 5483-5490. https://doi.org/10.1128/ JCM.43.11.5483-5490.2005.

Chinivasagam, H.N., Tran, T., Maddock, L., Gale, A., Blackall, P.J., 2009. Mechanically ventilated broiler sheds: a possible source of aerosolized Salmonella, Campylobacter, and Escherichia coli. Appl. Environment. Microbiol. 75 (23), 7417-7425. https://doi. org/10.1128/AEM.01380-09.

Cosby, D.E., Cox, N.A., Harrison, M.A., Wilson, J.L., Buhr, R.J., Fedorka-Cray, P.J., 2015. Salmonella and antimicrobial resistance in broilers: a review. J. Appl. Poult. Res. 24, 408-426. https://doi.org/10.3382/japr/pfv038.

Dar, M.A., Ahmad, S.M., Bhat, S.A., Ahmed, R., Urwat, U., Mumtaz, P.T., Bhat, S.A., Dar, T.A., Shah, R.A., Ganai, S.H., 2017. Salmonella typhimurium in poultry: a review. Worlds Poult. Sci. J. 72 (3), 345-354. https://doi.org/10.1017/ S0043933917000204.

Davies, R.H., Breslin, M., 2003. Persistence of Salmonella Enteritidis phage type 4 in the environment and arthropod vectors on an empty free-range chicken farm. Environ. Microbiol. 5 (2), 79-84. https://doi.org/10.1046/j.1462-2920.2003.00387.x.

Deblais, L., Lorentz, B., Scaria, J., Nagaraja, K.V., Nisar, M., Lauer, D., Voss, S., Rajashekara, G., 2018. Comparative genomic studies of Salmonella Heidelberg isolated from chicken- and turkey-associated farm environmental samples. Front. Microbiol. 9, 1841. https://doi.org/10.3389/fmicb.2018.01841.

Giombelli, A., Gloria, M.B.A., 2014. Prevalence of Salmonella and Campylobacter on broiler chickens from farm to slaughter and efficiency of methods to remove visible fecal contamination. J. Food Prot. 77 (11), 1851-1859. https://doi.org/10.4315/ 0362-028X.JFP-14-20.

Gradel, K.O., Rattenborg, E., 2003. A questionnaire-based, retrospective field study of persistence of Salmonella Enteritidis and Salmonella Typhimurium in Danish broiler houses. Prev. Vet. Med. 56 (4), 267-284. https://doi.org/10.1016/S0167-5877(02) 00211-8.

Hoffmann, M., Zhao, S., Pettengill, J., Luo, Y., Monday, S.R., Abbott, J., Ayers, S.L., Cinar, H.N., Muruvanda, T., Li, C., Allard, M.W., Whichard, J., Meng, J., Brown, E.W., McDermott, P.F., 2014. Comparative genomic analysis and virulence differences in closely related Salmonella enterica serotype Heidelberg isolates from humans, retail meats, and animals. Genome Biol. Evol. 6 (5), 1046-1068. https://doi.org/10.1093/ gbe/evu079.

Marin, C., Lainez, M., 2009. Salmonella detection in feces during broiler rearing and after live transport to the slaughterhouse. Poult. Sci. 88 (9), 1999-2005. https://doi.org/ 10.3382/ps.2009-00040.

Marin, C., Hernandiz, A., Lainez, M., 2009. Biofilm development capacity of Salmonella strains isolated in poultry risk factors and their resistance against disinfectants. Poult. Sci. 88 (2), 424-431. https://doi.org/10.3382/ps.2008-00241.

Mueller-Doblies, D., Sayers, A.R., Carrique-Mas, J.J., Davies, R.H., 2009. Comparison of sampling methods to detect Salmonella infection of turkey flocks. J. Appl. Microbiol. 107 (2), 635-645. https://doi.org/10.1111/j.1365-2672.2009.04230.x.
Mueller-Doblies, D., Carrique-Mas, J.J., Davies, R.H., 2014. A study of the dynamics of Salmonella infection in turkey breeding, rearing and finishing houses with special reference to elimination, persistence and introduction of Salmonella. Avian Pathol. 43 (2), 146-154. https://doi.org/10.1080/03079457.2014.892569.

Oladeinde, A., Cook, K., Orlek, A., Zock, G., Herrington, K., Cox, N., Lawrence, J.P., Hall, C., 2018. Hotspot mutations and ColE1 plasmids contribute to the fitness of Salmonella Heidelberg in poultry litter. PLoS One 13 (8), e0202286. https://doi.org/ 10.1371/journal.pone.0202286.

Pandini, J.A., da Silva Pinto, F.G., Muller, J.M., Weber, L.D., Moura, A.C., 2015. Occurrence and antimicrobial resistance profile of Salmonella spp. serotypes isolated from poultry farms in Paraná, Brazil. Arq. Inst. Biol. 82. https://doi.org/10.1590/ 1808-1657000352013.

Pedersen, T.B., Olsen, J.E., Bisgaard, M., 2008. Persistence of Salmonella Senftenberg in poultry production environments and investigation of its resistance to desiccation. Avian Pathol. 37 (4), 421-427. https://doi.org/10.1080/03079450802216561.

Pulido-Landínez, M., Sanchez-Ingunza, R., Guard, J., do Nascimento, V.P., 2013. Assignment of serotype to Salmonella enterica isolates obtained from poultry and their environment in southern Brazil. Lett. Appl. Microbiol. 57 (4), 288-294. https://doi. org/10.1111/lam.12110.

Ribot, E.M., Fair, M.A., Gautom, R., Cameron, D.N., Hunter, S.B., Swaminathan, B. Barrett, T.J., 2006. Standardization of pulsed-field gel electrophoresis protocols for the subtyping of Escherichia coli O157:H7, Salmonella, and Shigella for PulseNet. Foodborne Pathog. Dis. 3 (1), 59-67. https://doi.org/10.1089/fpd.2006.3.59.

Roll, V.F., Dai Prá, M.A., Roll, A.P., 2011. Research on Salmonella in broiler litter reused for up to 14 consecutive flocks. Poult. Sci. 90 (10), 2257-2262. https://doi.org/10. 3382/ps.2011-01583.

Rose, N., Beaudeau, F., Drouin, P., Toux, J.Y., Rose, V., Colin, P., 2000. Risk factors for Salmonella persistence after cleansing and disinfection in French broiler-chicken houses. Prev. Vet. Med. 44, 9-20.

Thaxton, Y.V., Balzli, C.L., Tankson, J.D., 2003. Relationship of broiler flock numbers to litter microflora. J. Appl. Poult. Res. 12, 81-84. https://doi.org/10.1093/japr/12. 1.81 .

Van Immerseel, F., de Buck, J., Pasmans, F., Bohez, L., Boyen, F., Haesebrouck, F., Ducatelle, R., 2004. Intermittent long-term shedding and introduction of carrier birds after infection of chickens early posthatch with a low or high dose of Salmonella Enteritidis. Poult. Sci. 83 (11), 1911-1916. https://doi.org/10.1093/ps/83.11.1911.

Vaz, C.S.L., Voss-Rech, D., de Avila, V.S., Coldebella, A., Silva, V.S., 2017. Interventions to reduce the bacterial load in recycled broiler litter. Poult. Sci. 96 (8), 2587-2594. https://doi.org/10.3382/ps/pex063.

Volkova, V.V., Bailey, R.H., Rybolt, M.L., Dazo-Galarneau, K., Hubbard, S.A., Magee, D., Byrd, J.A., Wills, R.W., 2010. Inter-relationships of Salmonella status of flock and grow-out environment at sequential segments in broiler production and processing. Zoonoses Public Health 57 (7-8), 463-475. https://doi.org/10.1111/j.1863-2378. 2009.01263.x.

Voss-Rech, D., Vaz, C.S.L., Alves, L., Coldebella, A., Leão, J.A., Rodrigues, D.P., Back, A., 2015. A temporal study of Salmonella enterica serotypes from broiler farms in Brazil. Poult. Sci. 94 (3), 433-441. https://doi.org/10.3382/ps/peu081.

Voss-Rech, D., Trevisol, I.M., Brentano, L., Silva, V.S., Rebelatto, R., Jaenisch, F.R.F., Okino, C.H., Morés, M.A.Z., Coldebella, A., Botton, S.A., Vaz, C.S.L., 2017. Impact of treatments for recycled broiler litter on the viability and infectivity of microorganisms. Vet. Microbiol. 203, 308-314. https://doi.org/10.1016/j.vetmic.2017.03.020.

Xavier, L.H., 2000. Univariate and Multivariate Models for Analysis of Repeated Measures and Verification of the Accuracy of the Univariate Model through Simulation. Master's Thesis. Escola Superior de Agricultura Luiz de Queiroz, Universidade de São Paulo, Piracicaba, Brazil.

Yamazaki, W., Uemura, R., Sekiguchi, S., Dong, J.B., Watanabe, S., Kirino, Y., Mekata, H., Nonaka, N., Norimine, J., Sueyoshi, M., Goto, Y., Horii, Y., Kurogi, M., Yoshino, S., Misawa, N., 2016. Campylobacter and Salmonella are prevalent in broiler farms in Kyushu, Japan: results of a 2-year distribution and circulation dynamics audit. J. Appl. Microbiol. 120 (6), 1711-1722. https://doi.org/10.1111/jam.13141. 